\title{
Analisis Penerapan Kurikulum 2013 dalam Meningkatkan Kualitas Pembelajaran Kimia SMA NEGERI 3 Kota Bima
}

\author{
Arif Munandar ${ }^{1,}{ }^{*}$, Amiruddin $^{2}$ \\ ${ }^{1}$ Program studi Pendidikan Kimia STKIP Bima \\ 2Program Studi Pendidikan BK STKIP Bima \\ *email: Arifstkip16@
}

\begin{abstract}
ABSTRAK
SMA Negeri 3 Kota Bima adalah salah satu sekolah menengah yang melaksanakan Kurikulum 2013 pada tahun ajaran 2019/2020, guna meningkatkan prestasi siswanya. Penelitian ini bertujuan untuk mengetahui penerapan pembelajaran kimia dalam Kurikulum 2013 untuk mengetahui kualitas belajar siswa berbasis Kurikulum 2013 di SMA Negeri 3 Kota Bima. Metode penelitian yang digunakan dalam penelitian ini adalah kualitatif dengan mengunakan teknik analisis data menggunakan deskriptif kuantitatif, Metode pengumpulan data yang digunakan yaitu Observasi/pengamatan (observasi), dan Wawancara, Teknik pengumpulan data yang digunakan dalam penelitian ini, adalah Kuesioner dan angket. Hasil penelitian menunjukah bahwa penerapan kurikulum 2013 masih belum sepenuhnya di terapkan di SMA Negeri 3 Kota Bima khususnya pada mata pelajaran Kimia, karena guru kebanyakan masih sangat kurang memahami sistem belajar mengajar dengan kurikulum 2013. Kurikulum 2013 yang notabene menggunakan beberapa metode pembelejaran itu sangat jarang sekali, proses pembelajaran hanya menggunakan buku Lembar Kerja Siswa (LKS), dan buku cetak Kimia tuk SMA. Kurikulum 2013 sudah di terapkan di SMA Negeri 3 Kota Bima namum penerapannya masih mengalami kendala.
\end{abstract}

Kata Kunci: Penerapan Kurikulum 2013, Meningkatkan Kualitas, Pembelajaran Kimia

\section{PENDAHULUAN}

Manusia merupakan mahluk Tuhan yang otonom, pribadi yang tersusun atas kesatuan harmonik jiwa raga dan eksis individu yang memasyarakat. Manusia lahir dalam keadaan yang serba misterius (Kamaludin, 2012: 13). Sebagai mahluk yang unik dan sempurna di banding manusia lain di dunia, manusia juga mahluk alami yang hidup berdasarkan insting dan rasio. Manusia membutuhkan pendidikan dalam kehidupan kesehariannya, pendidikan merupakan usaha agar manusia dapat mengenal dan megembangkan potensi dirinya melalui proses pembelajaran., dengan potensi akal, manusia cenderung berkeinginan untuk memperoleh ilmu pengetahuan sebanyakbanyaknya.

Pendidikan pada jalur pendidikan sekolah dan luar sekolah perlu mengadakan penelaahan ulang. Rancangan Kurikulum yang dikembangkan dan dilaksanakan, program-program jenjang pendidikan dasar, menengah dan pendidikan tinggi merupakan program-program yang berkesinambungan, jalur pendidikan terdiri atas pendidikan formal, non formal, dan informal yang saling melengkapi dan memperkaya, jenjang pendidikan formal terdiri atas, pendidikan menengah dan pendidikan tinggi. Program pengembangan kurikulum pada jenjang pendidikan (Sekolah Dasar/Sekolah 
Menengah) harus dapat menjadi dasar pengembangan dan perluasan pengetahuan, sikap dan keterampilan peserta didik pada pendidikan seumur hidup.

Kurikulum merupakan salah satu komponen yang harus ada dalam sebuah kurikulum, Tujuan pengembangan kurikulum erat kaitannya dengan arah dan sasaran yang harus dicapai oleh setiap upaya pendidikan, mendesain model-model kurikulum yang dapat digunakan sehingga akan membantu pendidik dalam mendesain sistem pembelajaran, dan mengontrol dalam menentukan batas-batas dan kualitas pembelajaran (Munandar, 2018: 31). Bloom (1965) merumuskan klasifikasi atau 3 domain dalam membentuk perilaku: Pertama. Kognitif: Merupakan Tujuan Pendidikan yang berhubungan dengan kemampuan berfikir seperti mengingat dan kemampuan memecahkan masalah. Kedua. Afektif: Domain afektif berkenaan dengan sikap, nilai-nilai dan presiasi. Ketiga. Psikomotorik: merupakan tujuan yang berhubungan dengan kemampuan keterampilan (Munir, 2008: 5).

Komponen dari sistem pendidikan nasional harus senantiasa dikembangkan sesuai dengan kebutuhan dan perkembangan yang terjadi, baik pada tingkat lokal, nasional maupun global. Salah satu komponen penting dari sistem pendidikan adalah kurikulum (SDM) (Ahmad, 2018). Hadirnya Kurikulum 2013 di Sekolah Menengah Atas (SMA) sebagai kurikulum baru didalam dunia pendidikan nasional diharapkan dapat lebih menyempurnakan kurikulum sebelumnya yaitu mulai KTSP (Kurikulum Tingkat Satuan Pendidikan) sampai dengan Kurikulum 2013. Penyempurnaan ini, dilaksanakan guna meningkatkan sistem pendidikan nasional agar selalu relevan dan kompetitif (Arif Munandar, 2016). Keberhasilan pelaksanaan Kurikulum 2013 tidak hanya pada ketepatan dan komprehensif perumusan substansi kurikulum, tetapi dari kepemimpinan kepala sekolah pada tingkat satuan pendidikan dan kepemimpinan guru pada tingkat kelas (Suyatmini. 2017). Kepemimpinan kepala sekolah mempunyai peran penting dalam memfasilitasi guru dalam melaksanakan proses belajar mengajar di kelas untuk menerapkan kurikulum 2013, Sedangkan kepemimpinan guru di tingkat kelas jelas menjadi bagian yang tidak bisa dipisahkan dengan keberhasilan dalam pelaksanaan Kurikulum 2013 (Rosmiaty, 2018).

\section{METODE}

\section{Rancangan Penelitan.}

Penelitian ini dilaksanakan di SMAN 3 Kota Bima dengan alasan sekolah tersebut merupakan sekolah yang pertama kali melaksanakan dan menerapkan kurukulum 2013, sehingga terdapat data yang diperlukan oleh peneliti yang memungkinkan untuk digunakan sebagai obyek penelitian. Penelitian merupakan penelitian kualitatif. Data dikumpulkan melalui Observasi/pengamatan (observasi), dan Wawancara dengan sumber data adalah seluruh guru yang mengajar mata pelajaran kimia di kelas X SMA Negeri 3 Kota Bima

\section{Teknik Pengumpulan Data}

Teknik pengumpulan data yang digunakan dalam penelitian ini, adalah Kuesioner dan angket. Kuesioner yang digunakan dalam penelitian ini termasuk ke dalam bentuk angket berstruktur dengan jawaban tertutup dan angket berstruktur dengan jawaban terbuka guna mengungkap bagaimana analisis implementasi Kurikulum 2013 dalam proses pembelajaran di SMA Negeri 3 Kota Bima 
Tabel 1. Kisi-kisi Instrumen untuk Kuesioner Terbuka Impelementasi Kurikulum 2013 dalam Proses Pembelajaran

\begin{tabular}{|c|c|c|c|c|}
\hline Variabel & Indikator & Deskriptor & $\begin{array}{c}\text { No } \\
\text { Item }\end{array}$ & $\begin{array}{c}\text { Jumlah } \\
\text { Butir }\end{array}$ \\
\hline \multirow{6}{*}{$\begin{array}{c}\text { Analisis Penerapan Kurikulum } \\
2013 \text { dalam proses } \\
\text { pembelajaran }\end{array}$} & \multirow{2}{*}{$\begin{array}{l}\text { Perencanaan } \\
\text { Pembelajaran }\end{array}$} & $\begin{array}{c}\text { Hambatan } \\
\text { yang dialami }\end{array}$ & \multirow{2}{*}{ A } & \multirow{2}{*}{1} \\
\hline & & $\begin{array}{l}\text { Solusi yang } \\
\text { diterapkan }\end{array}$ & & \\
\hline & Pelaksanaan & $\begin{array}{c}\text { Hambatan } \\
\text { yang dialami }\end{array}$ & \multirow{2}{*}{ B } & \multirow{2}{*}{1} \\
\hline & Pembelajaran & $\begin{array}{l}\text { Solusi yang } \\
\text { diterapkan }\end{array}$ & & \\
\hline & \multirow{2}{*}{$\begin{array}{l}\text { Pelaksanaan Penilaian } \\
\text { Hasil Belajar Siswa }\end{array}$} & $\begin{array}{c}\text { Hambatan } \\
\text { yang dialami }\end{array}$ & \multirow{2}{*}{ C } & \multirow{2}{*}{1} \\
\hline & & $\begin{array}{l}\text { Solusi yang } \\
\text { diterapkan }\end{array}$ & & \\
\hline
\end{tabular}

\section{Teknik Analisis Data}

Teknik analisis data yang digunakan dalam penelitian ini, adalah analisis data model milles and hubermas. Keabsahan suatu penelitian kualitatif tergantung pada kredibilitas, transferabilitas, dependabilitas, dan convormnabilitas.

\section{HASIL DAN PEMBAHASAN}

\section{Pemahaman siswa dan penerapan kurikulum 2013 terhadap pembelajaran kimia di SMA 3 Kota Bima}

Hasil dari wawancara dengan siswa kelas X IPA I dan II bahwa siswa menganggap mata pelajaran kimia tidak menyenangkan, sulit, banyak hafalan dan banyak hitungan. Sugesti dari siswa terhadap mata pelajaran kimia sudah negatif. Ditambah lagi pembelajaran terkesan membosankan karena pembelajaran berlangsung guru menjelaskan materi, siswa mendengarkan, siswa mengerjakan latihan soal pada buku, dan siswa melakukan praktikum di laboratorium kimia.

Selain itu juga saat kegiatan pembelajaran berlangsung yaitu siswa tidak memiliki minat serta motivasi belajar, bahkan mereka sering mengabaikan proses belajar mengajar (bercerita sendiri), dan hanya sebagian kecil yang memperhatikan pelajaran yang terjadi dalam kelas tersebut. Bisa dikatakan sebagian besar siswa sangat pasif di dalam kelas. Ketika diminta untuk mengerjakan soal nampak sekali siswa-siwa kesulitan untuk menyelesaikan soal yang diberikan.

Hasil wawancara di atas sangat berbeda dengan konsep kurilulim 2013 bahwa di dalamnya terdapat komponen-komponen pembelajaran dalam tiga kategori utama, yaitu: guru, isi atau materi pembelajaran, dan peserta didik. Interaksi dari tiga komponen tersebut melibatkan metode pembelajaran, media pembelajaran, dan penataan lingkungan tempat belajar. Kurikulum 2013 menggunakan 3 (tiga) model pembelajaran utama (Permendikbud No. 103 Tahun 2014) yang diharapkan dapat membentuk perilaku saintifik, perilaku sosial serta mengembangkan rasa keingintahuan. Ketiga model tersebut adalah: model Pembelajaran Berbasis Masalah (Problem Based 
Learning), model Pembelajaran Berbasis Projek (Project Based Learning), dan model Pembelajaran Melalui Penyingkapan/Penemuan (Discovery/Inquiry Learning).

Namun berbeda dengan penjelasan dari Kepala Sekolah SMA 3 Kota Bima Drs. Syaiful, M.Pd, tentang Penerapan Kurikulum 2013. Belajar dalah proses yang dapat memungkinkan tercapainya tujuan belajar baik segi kognitif, afektif, maupun psikomotor. maka metode pembelajaran diarahkan untuk mencapai sasaran tersebut, yaitu lebih banyak menekankan pembelajaran melalui proses. Dalam hal ini guru dituntut agar mampu memahami kedudukan metode pembelajaran sebagai salah satu komponen yang ikut andil dalam keberhasilan kegiatan belajar mengajar. Metode pembelajaran di kelas bukan hanya metode ceramah, diskusi dan latihan soal. Guru juga mencari metode belajar lainnya guna pembelajaran di kelas tidak membosankan dan peserta didik semangat untuk belajar.

Menurut Wakasek Kurikulum SMA Negeri 3 Kota Bima Drs.M.Saleh A.Hamid, dalam Penerapan Kurikulum 2013, menyatakan: Individu adalah makhluk yang unik memiliki kecenderungan, kecerdasan, dan gaya belajar yang berbeda-beda. Paling tidak ada 4 gaya belajar siswa seperti yang dikatakan oleh Howard Gardner yaitu Auditory, Visual, Reading dan Kinesthetic. Guru perlu menyadari bahwa siswa dalam satu kelas memiliki gaya belajar yang berbeda-beda. Oleh karena itu, untuk mengakomodir semua siswa belajar dengan latar belakang yang berbeda tersebut guru dapat menggunakan metode yang bervariasi.

\section{Penggunaan metode dan media pembelajaran berbasis kurikulum 2013 dalam pembelajaran kimia di SMA 3 Kota Bima.}

Hasil penelitian ini menjelaskan bahawa Pemanfaatan media pembelajaran di SMA Negeri 3 Kota Bima belum maksimal. Proses pembelajaran dilaksanakan dengan ceramah, diskusi, dan latihan soal. Proses pembelajaran juga hanya menggunakan buku Lembar Kerja Siswa (LKS), dan buku cetak Kimia untuk SMA. Penggunaan LCD hanya pada file presentasi, belum sampai pada video-video atau ilustrasi-ilustrasi lainnya tentang kimia, dan belum menggunakan alat peraga sebagai media penunjang pembelajaran kimia.

Hasil wawancara dengan dua guru kimia yaitu (Ibu Guru Arina Maisa S.Pd dan Ovi Chinta Kristina, S. Pd) Materi pelajaran Kimia yang seharusnya dilaksanakan praktikum terkadang tidak terlaksanakan hanya pembelajaran seperti biasa di kelas dan ternyata guru kimia kelas $X$ di SMA Negeri 3 Kota Bima, adalah lulusan Guru Kimia.

Penggunaan laboratorium perlu dimaksimalkan. Hasil wawancara dengan beberapa siswa dan megatakan bahwa mereka menyukai pembelajaran seperti praktik langsung di laboratorium. Hal ini dikarenakan jika praktik langsung akan membuat siswa jauh lebih paham dan mengerti mengenai materi yang diajarkan daripada jika teori saja di kelas. Praktikan wajib mempunyai disiplin tinggi, dan menaati tata tertib di laboratorium kimia. 


\section{Kualitas Pembelajaran Kimia di SMA 3 Kota Bima setelah penerapan kurikulum 2013}

Berdasarkan hasil penelitian ini bahwa kualitas pembelajaran kimia di SMA 3 Kota Bima tidak mengalami peningkatan sama sekali, dapat di lihat bahwa siswa cederung mengabaikan saat mata pelajaran kimi berlangsung. Kurikulum 2013 sudah sangat prporsional namun implementasi dari guru-guru pada tingkat satuan kelas masih sangat kurang bahkan masih cenderung tidak menegerti dengan konsep dan penerapan Kurikulum 2013. Selain itu kendalam yang cukup banyak adalah fasilitas yang disediakan oleh sekolah sangat kurang memadai, karena kurikulum 2013 fasilitas pendukung adalah yang paling utama, contohnya seperti laboratorium. Andi Wira Gunawan dalam buku "Genius Learning Strategy", mengatakan bahwa sesungguhnya tidak ada mata pelajaran yang membosankan, yang ada adalah guru yang membosankan, suasana belajar yang membosankan. Hal ini terjadi karena proses belajar berlangsung secara monoton dan merupakan proses perulangan dari itu ke itu juga tidak memiliki variasi atau belajar satu arah.

Wawancara dengan Guru Kimia Kelas X Ibu Khairunnisa, S. Pd: Penataan laboratorium sesuai dengan standar. Standar-standar berdasarkan keselamatan praktikan juga. Bahan-bahan kimia sebaliknya diletakkan di tempat yang aman. Laboratorium mempunyai lemari penyimpanan bahan-bahan kimia, administrasi laboratorium, wastafel yang tidak hanya satu, lemari yang khusus untuk menyimpan alat-alat laboratorium, meja praktikum, peralatan laboratorium yang memadai, ketersediaan energi listrik, gas, air, papan tulis, kotak obat-obatan, peralatan $P 3 K$, alat komunikasi, ruang ber AC untuk alat-alat yang memerlukan persyaratan tertentu atau jika tidak ber AC jendela atau ventilasi harus lebar, pendukung keselamatan kerja seperti pemadam kebakaran, hidran, dan sebagainya, dan tempat pembuangan untuk bahan-bahan kimia. Menurut Ibu Khairunnisa, Lanjutnya Tidak bisa di pungkiri laboratorium merupakan salah satu penunjang dalam pembelajaran kimia.

Lebih lanjut Guru Kimia kelas X menyampikan: Pembelajaran dilaksanakan dengan menggunakan metode yang interaktif, inspiratif ,menyenangkan, kreatif, menantang dan memotivasi peserta didik dengan seorang guru diharapkan memiliki kecakapan dalam melaksanakan kegiatan atau proses belajar mengajar dengan penguasaan materi pelajaran, ketepatan atau kecakapan pemilihan penggunaan materi mengajar, ketepatan pemilihan metodologi dan media serta sumber belajar hingga menyiapkan alat evualasi yang efektif. Tetapi untuk sementara karena Covid 19 (corona)dilakukan proses pembelajaran melalui daring.

Media pembelajaran adalah bahan, alat atau teknik yang digunakan dalam kegiatan belajar mengajar dengan maksud agar proses interaksi komunikasi edukasi antara guru dan siswa dapat berlangsung secara tepat guna dan berdayaguna. Metode pembelajaran yang ditetapkan guru memungkinkan siswa untuk belajar proses, bukan hanya belajar produk. Belajar produk pada umumnya hanya menekankan pada segi kognitif. Sedangkan belajar proses dapat memungkinkan tercapainya tujuan belajar baik segi kognitif, afektif, maupun psikomotor. Guru dituntut agar mampu menggunakan 
alat-alat yang dapat disediakan oleh sekolah, dan tidak tertutup kemungkinan bahwa alat-alat tersebut sesuai dengan perkembangan dan tuntutan zaman.

\section{KESIMPULAN}

Kurikulum 2013 sudah diterapkan di SMA 3 Kota Bima, namun implemetrasinya pada tingkat satuan kelas masih sangat kurang, karena guru-guru masih banyak yang belum memahami penerapanya pada matapelajaran, khususnya matapelajaran kimia.

\section{UCAPAN TERIMAKASIH}

Terimakasih kepada RISTEKDIKTI sudah membantu menyediakan dana penelitian pada penelitian ini sehingga, dapat telakasan tepat pada waktunya.

\section{DAFTAR PUSTAKA}

Damsar. 2012. Pengantar Sosiologi Pendidikan. Kencana Prenad

Hidayat A. W. 2018. Pengembangan dan Implementasi Kurikulum Pendidikan agama Islam Di SDN Demangan Yogyakarta. Jurnal Tarbiyatuna, Vol. 9 (2) 82-98

Lestari N. D. 2018. Analisis Penerapan Kurikulum 2013 Dalam Meningkatkan Kualitas Pembelajaran Ekonomi Di SMA Negeri Se-Kota Palembang. Jurnal Neraca. Vol 2 (1) 68-79.

Munandar A. 2018. Pengantar Kurikulum. Yogyakarta: Deepublish

Munandar A. (2016. Rekonstruksi UU Sistem Pendidikan Nasional membangun Negara Islam. Jurnal Mandala. Vol. 2 (1) 393-405.

Munandar A. 2018. Kurikulum Sebagai Jantung Pendidikan. Asosiasi Pendidik dan Pengembang Pendidikan Indonesia Kerjasama Lembaga Penelitian dan Pendidikan. Mandala, Vol. (No) 52-61

Munandar A. 2017. Pengelolaan Pembelajaran IPA Terpadu di SMP Negeri 2 Kartasura Tahun Pelajaran 2015-2016. Jurnal IImiah Mandala Education (JIME). Vol. 3, (1) 218-224

Mulyasa, E. 2013. Pengembangan dan Implementasi Kurikulum 2013, Bandung: Remaja Rosdakarya.

Suyatmini. 2017. Implementasi Kurikulum 2013 Pada Pelaksanaan Pembelajaran Akuntansi Di Sekolah Menengah Kejuruan. Jurnal Pendidikan IImu Sosial. Vol 27, (1) $60-67$

Rosmiaty A. 2018. Implementasi Pengembangan Kurikulum. Jurnal, Vol. VII, (1) 43-50. Sholeh, H. 2013. Pengembangan Kurikulum Baru. Bandung: PT Remaja Rosdakarya. Syachruddin, Dkk. 2020. Telaah Kurikulum. (Cetakan Pertama). Banten: CV. AA RIZKI.

Tjahjono, A. 2013. Petujuk Teknis Persiapan Implementasi Kurikulum Tahun 2013 pada Minggu Pertama di Sekolah. Direktorat Jendral Pendidikan Menengah Kementerian Pendidikan dan Kebudayaan.

Wisnu N. A. dan Ngumarno .2017. Implementasi Kurikulum 2013 Mata Pelajaran Bahasa Indonesia Di Kabupaten Klaten. Varia Pendidikan, Vol. 29, (1) 1-8.

Yusuf W. F. 2018. Implementasi Kurikulum 2013 (K-13) Pada Mata Pelajaran Pendidikan Agama Islam Sekolah Dasar (SD). Jurnal al-Murabbi. Vol. 3 (1) 263-278. 
Yunaryo, A. 2012. Implementasi Kurikulum Tingkat Satuan Pendidikan di Sekolah Dasar Masjid Syuhada. Yogyakarta. Laporan Penelitian. Universitas Negeri Yogyakarta 